\title{
Attenuation of inflammatory-mediated neurotoxicity by Saururus chinensis extract in LPS-induced BV-2 microglia cells via regulation of NF-KB signaling and anti-oxidant properties
}

\author{
Byung-Wook Kim¹, Sushruta Koppula', Shin-Young Park', Jin-Woo Hwang ${ }^{1}$, Pyo-Jam Park', Ji-Hong Lim²
} and Dong-Kug Choi ${ }^{*}$

\begin{abstract}
Background: A Saururus chinensis Baill (SC) has been used by Native Americans, early colonists and practitioners of Korean traditional medicine for treating several diseases including cancer, rheumatoid arthritis and edema. The objective of this study was to evaluate the effects of SC extract in lipopolysaccharide (LPS)-stimulated neuroinflammatory responses in BV-2 microglial cells.
\end{abstract}

Methods: The effects of SC on the LPS-induced neuroinflammatory responses in BV-2 microglial cells were assessed by Western blotting, RT-PCR and immunofluorescence labeling techniques. DPPH and alkyl radical scavenging assay was performed to evaluate the anti-oxidant effects. Comparisons between groups were analyzed using one-way analysis of variance followed by Dunnett's multiple comparisons test using GraphPad Prism V5.01 software.

Results: Pre-treatment with SC extract $(1,5$ and $10 \mu \mathrm{g} / \mathrm{mL})$ significantly $(p<0.001$ at $10 \mu \mathrm{g} / \mathrm{mL})$ and concentration dependently inhibited LPS-induced production of nitric oxide (NO), inducible NO synthase (iNOS), cyclooxygenase-2 (COX-2) and suppressed the inflammatory cytokine levels such as tumor necrosis factor-alpha and interleukin (IL)-6 in BV-2 microglial cells ( $p<0.001$ at $10 \mu \mathrm{g} / \mathrm{mL}$ ). Further, SC suppressed the nuclear factor-kappa B (NF-kB) activation by blocking the degradation of IKB-a. SC also exhibited profound anti-oxidant effects by scavenging 1, 1-diphenyl-2picrylhydrazyl (DPPH) (IC50: $0.055 \mathrm{mg} / \mathrm{mL}$ ) and alkyl radicals (IC50: $0.349 \mathrm{mg} / \mathrm{mL}$ ). High performance liquid chromatography finger printing analysis of SC revealed quercetin (QCT) as one of the major constituents compared with reference standard. QCT also inhibited the excessive release of NO, and inhibited the increased expressional levels of IL-6, iNOS and COX-2 in LPS-stimulated BV-2 cells.

Conclusions: Our results indicated that SC inhibited the LPS-stimulated neuroinflammatory responses in BV-2 microglia via regulation of NF-KB signaling. The antioxidant active constituents of SC might be partly involved in delivering such effects. Based on the traditional claims and our present results SC can be potentially used in treating inflammatory-mediated neurodegenerative diseases.

Keywords: Microglia, Saururus chinensis, Quercetin, LPS, NF-KB, Neurodegenerative disease

\footnotetext{
* Correspondence: choidk@kku.ac.kr

'Department of Biotechnology, Konkuk University, Chungju, Korea

Full list of author information is available at the end of the article
} 


\section{Background}

Microglia, the immune cells of the central nervous system (CNS), plays an important role in neuroinflammation. It was well documented that microglial activation increases the risk for several CNS diseases such as Alzheimer's disease, Parkinson's disease (PD), multiple sclerosis, and Huntington's disease [1-4]. Excessive activation of microglia due to pathogenic bacterial infection or injury releases proinflammatory mediators such as tumor necrosis factor (TNF)- $\alpha$, interleukin (IL)- $1 \beta$, IL-6, reactive oxygen species (ROS), nitric oxide (NO), inducible $\mathrm{NO}$ synthase (iNOS) and cyclooxygenase (COX)-2 [5]. Therefore, attenuation of neuroinflammatory events in microglia might be a promising strategy for preventing the progression of inflammatory-mediated neurodegenerative diseases.

Saururus chinensis Baill. (SC), a fragrant aquatic plant from the family Saururaceae has been used by Native Americans, early colonists and practitioners of Korean traditional medicine for treating a range of diseases including cancer, rheumatoid arthritis and nephritisassociated edema [6]. Pharmacological reports showed that SC possess anti-asthmatic [7,8], anti-oxidative [9-11], anti-angiogenic [12], anti-inflammatory $[7,10,12]$, antiatopic [13], anti-cancer [14] and hepatoprotective properties [15]. Based on these reports, complementary studies are needed to determine whether the beneficial effects of $\mathrm{SC}$ are applicable to the treatment of neuroinflammatory and neurodegenerative diseases. In the present study, we investigated the anti-neuroinflammatory effects of SC extract against LPS-stimulated BV-2 microglial cells and explored the underlying mechanisms. The antioxidant status of SC was also evaluated using in vitro free radical scavenging assays. Further, to identify the major constituents in SC extract used in the study, high performance liquid chromatography (HPLC) fingerprinting analysis was performed.

\section{Methods}

\section{Chemical materials}

Lipopolysaccharide (LPS) (E. coli 0111:B4), Tween20, bovine serum albumin (BSA), dimethyl sulfoxide (DMSO), 3-[4,5-dimethylthiazol-2-yl]-2,5 diphenyl tetrazolium bromide (MTT) and quercetin (QCT) were purchased from Sigma-Aldrich (St. Louis, MO, USA). Six-well and 96-well tissue culture plates and $100 \mathrm{~mm}$ culture dishes were purchased from Nunc Inc. (North Aurora, IL, USA). DMEM containing $4.5 \mathrm{~g} / \mathrm{L}$ D-glucose, L-arginine, $110 \mathrm{mg} / \mathrm{L}$ sodium pyruvate, and fetal bovine serum, as well as other cell culture reagents, TRIZOL and a Superscript ${ }^{\mathrm{Tm}}$-III kit were obtained from Gibco/Invitrogen (Carlsbad, CA, USA). The 10× RIPA buffer was purchased from Millipore (Milford, MA, USA). The protease inhibitor cocktail tablets, phosphatase inhibitor cocktail tablets were supplied by Roche (Indianapolis, IN, USA). Antibodies to nuclear factor (NF)- $\mathrm{kB}$ p65 and COX-2 were obtained from Santa Cruz Biotechnology (Santa Cruz, CA, USA). Antibodies for iNOS, IкB- $\alpha$, phosphor (p)-IкB- $\alpha$, and $\beta$-actin were supplied by Cell Signaling Technology (Danvers, MA, USA).

\section{Preparation of the SC extract}

Dried SC root material was purchased from a traditional herb market in Korea and authenticated by a taxonomist at the Plant Extract Bank, South Korea. A voucher specimen (CA02-047) was deposited at the institute's herbarium, Konkuk University. To obtain the ethanol extract, $100 \mathrm{~g}$ of dried root material was added to $1 \mathrm{~L}$ of $95 \%$ ethanol, and the extraction was performed with sonication at room temperature for $15 \mathrm{~min}$ with an interval of $2 \mathrm{~h}$ using a $40 \mathrm{kHz}$ model 8210R ultrasonic reactor (Branson Ultrasonic, Corp. Newtown, CT, USA). The procedure was repeated 15 times, and the mixture was filtered with $0.22 \mu \mathrm{M}$ type GV film (Millipore, Milford, MA, USA). The filtrate was combined, and the final product was concentrated with a rotary evaporator, lyophilized, and stored at $4^{\circ} \mathrm{C}$. The resulting powder (yield, $14.4 \mathrm{~g}$ ) was re-dissolved in DMSO $(0.1 \%)$ and filtered through a $0.22 \mu \mathrm{M}$ filter before use. Standard QCT was purchased from Sigma-Aldrich for the comparative experimental studies. The SC extract and QCT were subjected to analytical HPLC (Waters, Sudbury, ONT, Canada), equipped with a UV detector. A GROMSIL $120 C_{18}(4.0 \mathrm{~mm} \times 250 \mathrm{~mm})$ column was used.

\section{High-performance liquid chromatography (HPLC) finger print analysis}

A Waters liquid chromatography system (Waters Associates Inc., Bedford, MA, USA), equipped with a double pump and a photodiode array detector was used. Separation was carried out on a Cosmosil $5 \mathrm{C}_{18}$-AR-II column $(4.6 \mathrm{~mm} \times 250 \mathrm{~mm}, 5 \mu \mathrm{m})$ with a column temperature set to $25^{\circ} \mathrm{C}$. The mobile phases consisted of $0.4 \%$ aqueous phosphoric acid (A) and acetonitrile (B). For gradient elution the conditions were: $15 \% \mathrm{~B}(\mathrm{v} / \mathrm{v})$ at $0-16 \mathrm{~min}$, $15-25 \% \mathrm{~B}$ at $16-30 \mathrm{~min}, 25 \% \mathrm{~B}$ at $30-32 \mathrm{~min}, 25-30 \% \mathrm{~B}$ at $32-35 \mathrm{~min}, 30 \% \mathrm{~B}$ at $35-37 \mathrm{~min}, 30-33 \% \mathrm{~B}$ at $37-$ $40 \mathrm{~min}, 33 \% \mathrm{~B}$ at $40-45 \mathrm{~min}, 33-48 \% \mathrm{~B}$ at $45-55 \mathrm{~min}$, $48-55 \% \mathrm{~B}$ at $55-75 \mathrm{~min}, 55-80 \% \mathrm{~B}$ at $75-82 \mathrm{~min}, 80 \% \mathrm{~B}$ at $82-88 \mathrm{~min}$, and the re-equilibration time of the gradient elution was $15 \mathrm{~min}$. Flow rate was $0.8 \mathrm{~mL} / \mathrm{min}$, and injection volume was $10 \mu \mathrm{L}$. The detection wavelength for the QCT analyte was set to $360 \mathrm{~nm}$. The absorption spectrum of the compound was recorded at 200-500 nm. The compound was identified by comparing the retention time and UV spectrum with those of standard markers.

\section{Cell culture and viability assay}

BV-2 microglial cells were obtained and cultured as described previously [16]. Briefly, cells were seeded at a 
density of $5 \times 10^{5}$ cells $/ \mathrm{mL}$, pretreated for $1 \mathrm{~h}$ with various concentrations of SC $(1,5$, and $10 \mu \mathrm{g} / \mathrm{mL})$ and then incubated for $24 \mathrm{~h}$ in medium containing LPS $(100 \mathrm{ng} / \mathrm{mL})$. Then, $0.5 \mathrm{mg} / \mathrm{mL}$ MTT was added to each well. After $4 \mathrm{~h}$ incubation at $37^{\circ} \mathrm{C}$ and $5 \% \mathrm{CO}_{2}$, the supernatants were removed from each well, and the formed formazan crystals in the viable cells were dissolved in DMSO. Absorbance was determined at $540 \mathrm{~nm}$ using a microplate reader (Tecan Trading AG, Basel, Switzerland).

\section{NO production assay}

$\mathrm{NO}$ production was assayed by measuring the levels of nitrite in culture medium using a colorimetric assay with Griess reagent [17]. BV-2 cells $\left(5 \times 10^{4}\right.$ cells $\left./ \mathrm{mL}\right)$ were seeded in 96-well plates in $100 \mu \mathrm{L}$ culture medium and stimulated with LPS (100 ng/mL) for $24 \mathrm{~h}$. The culture supernatant $(50 \mu \mathrm{L})$ was reacted with an equal volume of Griess reagent $(0.1 \%$ naphthylethylenediamine and $1 \%$ sulfanilamide in $5 \% \mathrm{H}_{3} \mathrm{PO}_{4}$ ) in 96-well plates for $10 \mathrm{~min}$ at room temperature in the dark. Nitrite concentrations were determined using standard sodium nitrite solutions prepared in medium. The absorbance was determined at $540 \mathrm{~nm}$ using a microplate reader.

\section{Isolation of total RNA and reverse transcription polymerase chain reaction (RT-PCR)}

Total RNA was extracted using TRIZOL reagent according to the manufacturer's instructions. RNA $(2.5 \mu \mathrm{g})$ was reverse-transcribed using a Superscript ${ }^{\mathrm{Ts}}$-III kit according to the manufacturer's instruction. PCR amplification was conducted using specific primers sets at annealing temperatures of $53.5-58^{\circ} \mathrm{C}$ for $20-30$ cycles. The primer sequences used are presented in Table 1 . The PCR conditions were described previously [18].

\section{Western blot analysis}

Cells were washed twice with PBS, placed at $4^{\circ} \mathrm{C}$, and lysed for $10 \mathrm{~min}$ in lysis buffer (1× RIPA lysis buffer, protease inhibitor cocktail, phosphatase inhibitor cocktail). Lysates were centrifuged at $14000 \mathrm{rpm}$ and $4^{\circ} \mathrm{C}$, and the supernatants were collected for further analysis. Equal amounts of protein $(40 \mu \mathrm{g})$ were separated electrophoretically by $10 \%$ sodium dodecyl sulfate-polyacrylamide electrophoresis, and the resolved proteins were transferred to polyvinylidene difluoride membranes (Millipore). The membranes were incubated for $1 \mathrm{~h}$ with 5\% BSA in TPBT buffer to block nonspecific binding. The membranes were then incubated with primary antibodies to anti-iNOS, anti-IkB- $\alpha$, anti-phospho-IкB- $\alpha$ (1:1000; Cell Signaling Technology), anti- $\beta$-actin (1:2000; Cell Signaling Technology) and antiCOX-2 (1:1000; Santa Cruz Biotechnology). The blots were visualized using PowerOpti-ECL (Animal Genetics Inc, Tallahassee, FL, USA) detection system according to the manufacturer's procedure. Antibody-specific bands were scanned using a LAS-3000 luminescent analyzer, and quantified using Fuji Multigauge software V3.1 (Fuji, Tokyo, Japan).

\section{Double-immunofluorescence labeling assay}

BV-2 microglia cells $\left(1 \times 10^{5}\right.$ cells/well in a 12 -well plate $)$ were cultured on sterile cover slips in 12-well plates and treated with compounds and LPS to detect the intracellular location of the NF-kB p65 subunit. At 30 min after LPS treatment, the cells were fixed with methanol for $20 \mathrm{~min}$ at $-20^{\circ} \mathrm{C}$ and washed three times with PBS. The fixed cells were then permeabilized with $1 \%$ Triton X100 in PBS for $10 \mathrm{~min}$ at room temperature (RT), washed with $0.05 \%$ Tween 20 in PBS for $5 \mathrm{~min}$, followed by $0.05 \%$ Tween $20 / 1 \%$ BSA in PBS for $5 \mathrm{~min}$. The permeabilized cells were then treated with anti-NF- $\kappa B$ p65 (1:200; Santa Cruz Biotechnology) overnight at $4^{\circ} \mathrm{C}$ and washed with $0.05 \%$ Tween $20 / 1 \%$ BSA in PBS for $5 \mathrm{~min}$. The cells were then incubated in a 1:100 dilution of Alexa Fluor 568-labeled goat anti-mouse antibody (Invitrogen, Carlsbad, CA, USA) for $1 \mathrm{~h}$ at RT and washed with $0.05 \%$ Tween 20 in PBS for $5 \mathrm{~min}$, followed by PBS for $5 \mathrm{~min}$. The cells were then stained with $1 \mu \mathrm{M}$ Hoechst staining solution (Invitrogen) for $10 \mathrm{~min}$ at RT

Table 1 PCR primers used

\begin{tabular}{|c|c|c|c|}
\hline Gene target & Accession & Primer sequence & Size (bp) \\
\hline \multirow{2}{*}{ iNOS } & \multirow{2}{*}{ NM_010927 } & F 5'-CTTGCAAGTCCAAGTCTTGC-3 & \multirow{2}{*}{369} \\
\hline & & R 5'-GTATGTGTCTGCAGATGTGCTG-3 & \\
\hline \multirow{2}{*}{ COX-2 } & \multirow{2}{*}{ NM_011198 } & F 5'-ACATCCCTGAGAACCTGCAGT-3' & \multirow{2}{*}{414} \\
\hline & & R 5'-CCAGGAGGATGGAGTTGTTGT-3' & \\
\hline \multirow{2}{*}{ TNF-a } & \multirow{2}{*}{ NM_01369 } & F 5'-TTCGAGTGACAAGCCTGTAGC-3 & \multirow{2}{*}{390} \\
\hline & & R 5'-AGATTGACCTCAGCGCTGAGT-3' & \\
\hline \multirow{2}{*}{ IL-6 } & \multirow{2}{*}{ NM_031168 } & F 5'-CATATGAGCTGAAAGCTCTCCA-3' & \multirow{2}{*}{435} \\
\hline & & R 5'-GACACAGATTCCATGGTGAAGTC-3' & \\
\hline \multirow{2}{*}{ GAPDH } & \multirow{2}{*}{ GU214026 } & F 5'-CCAGTATGACTCCACTCACG-3 & \multirow{2}{*}{378} \\
\hline & & R 5'-CCTTCCACAATGCCAAAGTT-3 & \\
\hline
\end{tabular}


and then washed. Finally, all images were captured with a Carl Zeiss Axio 40 fluorescence microscope (Carl Zeiss, Oberkochen, Germany).

\section{Measurement of free radical scavenging activity}

Free radical scavenging activity was evaluated using an electron spin resonance (ESR) spectrometer (JEOL, Tokyo, Japan). DPPH radical scavenging activity was measured using a method described previously [19]. A sample solution of SC $(30 \mu \mathrm{L})$ was added to $60 \mu \mathrm{M}$ DPPH $(30 \mu \mathrm{L})$ in methanol and incubated for 2 min. Alkyl radicals were generated by 2,2'-azobis (2-amidinopropane) hydrochloride $(\mathrm{AAPH})$. The reaction mixture containing $10 \mathrm{mM}$ AAPH $(20 \mu \mathrm{L}), 10 \mathrm{mM}$ 4-POBN $(20 \mu \mathrm{L})$, and SC $(20 \mu \mathrm{L})$ of various concentrations in PBS $(20 \mu \mathrm{L}, \mathrm{pH} 7.4)$ was incubated at $37^{\circ} \mathrm{C}$ in a water bath for $30 \mathrm{~min}$. The ESR spectrum was recorded for each radical using an ESR spectrometer.

\section{Statistical analysis}

Data are expressed as means \pm standard errors of mean (S.E.M). Each value was the result of three independent experiments $(n=3)$. Comparisons between groups were analyzed using one-way analysis of variance followed by Dunnett's multiple comparisons test using GraphPad Prism V5.01 software (GraphPad Software Inc., San Diego, CA, USA). P-values $<0.05$ were considered significant.

\section{Results}

\section{SC extract attenuated LPS-induced nitrite production in} BV-2 microglial cells

To determine the cytotoxic potential of the SC extract, we evaluated its effects on the viability of BV-2 microglial cells at $5 \times 10^{4}$ cells $/ \mathrm{mL}$. The MTT assay was performed $24 \mathrm{~h}$ after treatment with various concentrations $(1-10 \mu \mathrm{g} / \mathrm{mL})$ of SC in the presence or absence of LPS (100 ng/mL). Treatment with SC alone or with LPS $(100 \mathrm{ng} / \mathrm{mL})$ did not result in any signs of cytotoxicity at the indicated concentrations (Figure 1A). The vehicle (0.1\% DMSO) used to dissolve SC also did not show any effect on overall cell viability as determined by the MTT assay (data not shown). To evaluate the effect of SC on $\mathrm{NO}$ production, $\mathrm{BV}-2$ microglia cells were pretreated with 1,5 , and $10 \mu \mathrm{g} / \mathrm{mL} \mathrm{SC}$ for $1 \mathrm{~h}$ and then stimulated with LPS (100 ng/mL). The culture medium from the cells was harvested and assayed for NO generation. Stimulation with LPS significantly increased $(\mathrm{p}<0.001)$ the release of $\mathrm{NO}$ compared with that in the control group (Figure 1B). However, pretreatment with SC (1, 5, and $10 \mu \mathrm{g} / \mathrm{mL})$ inhibited NO release in LPS-stimulated BV-2 cells in a concentration-dependent manner (Figure 1B).

\section{SC suppressed LPS-induced iNOS and COX-2 expression in BV-2 microglia cells}

As shown in Figure 2A and Figure 2B, treatment with LPS increased iNOS mRNA expression at $6 \mathrm{~h}$ and iNOS protein expression at $18 \mathrm{~h}$, respectively $(\mathrm{p}<0.001)$. However, pretreatment with SC significantly attenuated LPSinduced iNOS mRNA and iNOS protein expression. These data indicate that SC suppresses LPS-induced NO production by inhibiting iNOS expression. COX-2 mRNA and protein levels were also significantly suppressed by SC in LPS-stimulated BV-2 cells. As shown in Figure $2 \mathrm{C}$ and Figure 2D, LPS treatment significantly up regulated COX2 mRNA and protein expression. However, pretreatment with $\mathrm{SC}(1,5$, and $10 \mu \mathrm{g} / \mathrm{mL})$ significantly $(\mathrm{p}<0.01$ at $5 \mu \mathrm{g} / \mathrm{mL}$ and $\mathrm{p}<0.001$ at $10 \mu \mathrm{g} / \mathrm{mL}$ ) and concentration dependently reduced this increase in LPS-stimulated BV-2 cells. These data correlated well with the reduction in protein and corresponding mRNA levels.

\section{SC extract inhibited LPS-induced TNF- $a$ and IL- 6 production in BV-2 microglial cells}

Proinflammatory cytokines such as TNF- $\alpha$, IL-1 $\beta$, and IL-6 are stimulators and/or co-stimulators of iNOS gene expression and play major roles in inflammatory disease
(A)

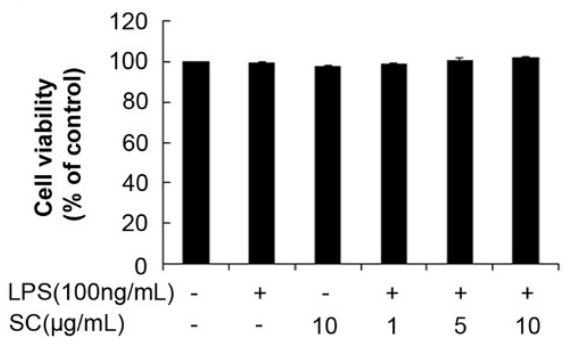

(B)

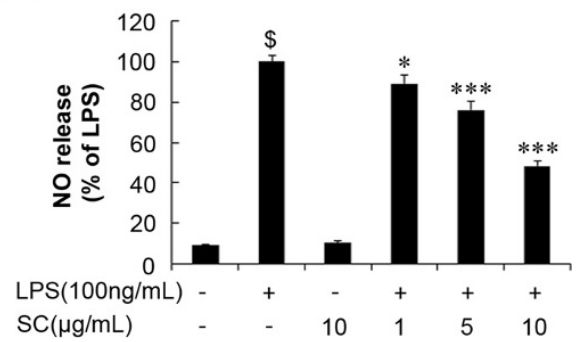

Figure 1 Effect of the SC extract on nitrite production in LPS-stimulated BV-2 microglia. Viability in SC-treated cells was evaluated using the MTT assay (A). Cells were incubated with 1, 5, and $10 \mu \mathrm{g} / \mathrm{mL}$ of SC and LPS (100 ng/mL) for 24 h. Results are displayed as a percentage of control samples. Nitrite in the medium was determined by the Griess assay (B). Results are displayed as a percentage of the LPS treated group. Data are mean \pm standard error $(n=3)$ of three independent experiments. ${ }^{\$} p<0.001$, compared with control group; ${ }^{*} p<0.05$ and ${ }^{* * *} p<0.001$ compared with LPS-treated group. SC: Saururus chinensis, LPS: lipopolysaccharide, MTT: 3-[4,5-dimethylthiazol-2-yl]-2,5 diphenyl tetrazolium bromide. 


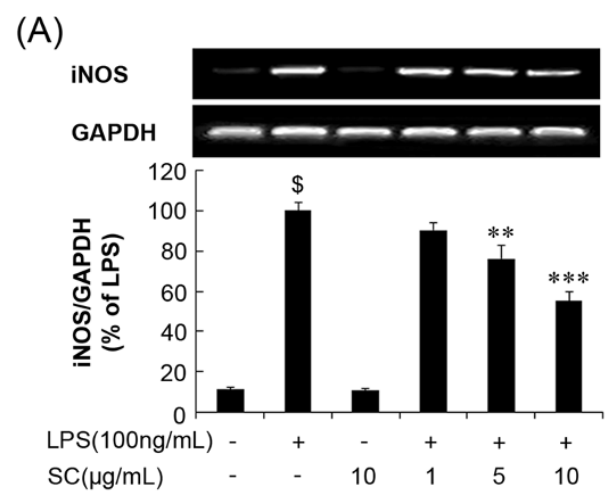

(C)

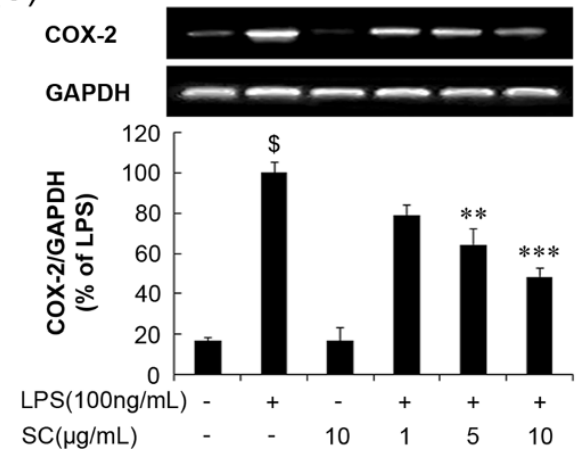

(B)

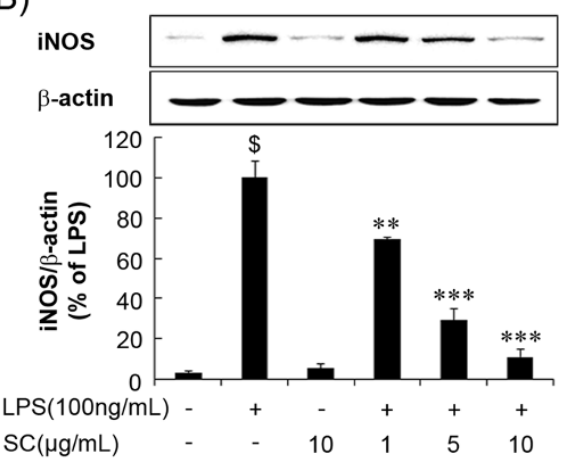

(D)

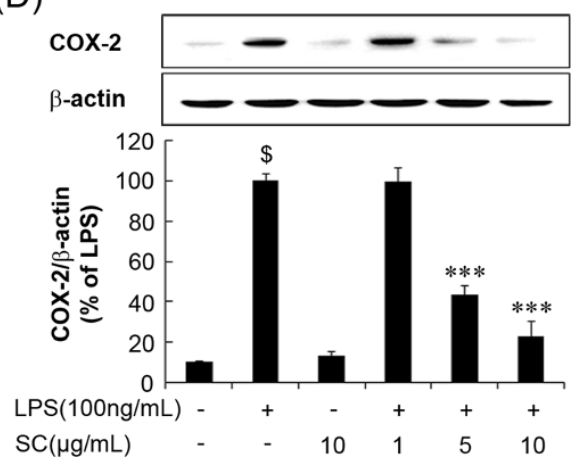

Figure 2 Inhibition of inducible nitric oxide synthase (iNOS) and cyclooxygenase (COX)-2 mRNA and protein expression by the SC extract in LPS-stimulated BV-2 microglia. (A, C) Cells were pretreated with the indicated concentrations of SC (1, 5, and $10 \mu \mathrm{g} / \mathrm{ml}) 1 \mathrm{~h}$ before stimulation for $6 \mathrm{~h}$ with $100 \mathrm{ng} / \mathrm{mL}$ LPS. Total RNA was prepared for reverse transcription-polymerase chain reaction analysis of iNOS and COX-2 gene expression from LPS-stimulated BV-2 microglia. (B, D) Cell lysates were electrophoresed, and iNOS and COX-2 expression was detected by a specific antibody. Data are mean \pm standard error $(n=3)$ for three independent experiments. ${ }^{\$} p<0.001$, compared with control group; ${ }^{* *} p<0.01$ and ${ }^{* * *} \mathrm{p}<0.001$ compared with LPS-treated group. SC: Saururus chinensis, LPS: Lipopolysaccharide.

[20,21]. To investigate whether the SC extract had any effect on the production of proinflammatory cytokines (TNF- $\alpha$ and IL-6), BV-2 microglia were stimulated with LPS $(100 \mathrm{ng} / \mathrm{mL})$ in the presence or absence of SC at the indicated concentrations $(1,5$ and $10 \mu \mathrm{g} / \mathrm{mL})$. RTPCR analysis showed that the mRNA levels of these cytokines increased $6 \mathrm{~h}$ after LPS treatment $(\mathrm{p}<0.001)$. Pretreatment with $\mathrm{SC}$ for $1 \mathrm{~h}$ attenuated the upregulation of TNF- $\alpha$ and IL- 6 in a concentration-dependent manner (Figure 3A and Figure 3B). These data suggest that SC inhibits the production of TNF- $\alpha$ and IL- 6 by mediating regulatory gene expression at the transcriptional level, which is involved in the microglia-mediated inflammatory process.

\section{SC regulated NF-KB activation in LPS-induced BV-2 microglial cells}

A previous study reported that LPS increases activation of the NF- $k B$ subunit (via phosphorylation, ubiquitination, degradation and translocation of p65 and ІкB-a) and regulates the expression of iNOS, COX-2, and other pro-inflammatory cytokines [22,23]. Therefore, we performed double-immunofluorescence labeling assay studies to investigate whether the SC extract inhibited NF- $\mathrm{KB}$ translocation in LPS-stimulated BV-2 microglial cells. Interestingly, SC blocked nuclear translocation of the NF$\kappa B$ p65 subunit (Figure 4A). To evaluate the effect of SC on IкB- $\alpha$ phosphorylation, BV-2 microglia were pretreated with SC $(1,5$, and $10 \mu \mathrm{g} / \mathrm{mL})$ for $1 \mathrm{~h}$ and then stimulated with LPS $(100 \mathrm{ng} / \mathrm{mL})$ for $30 \mathrm{~min}$. IкB- $\alpha$ phosphorylation increased significantly $(\mathrm{p}<0.001)$ after LPS treatment and translocation of the NF- $\mathrm{kB}$ p 65 subunit was induced into the nucleus. SC pretreatment suppressed ІкB- $\alpha$ phosphorylation in a concentration-dependent manner (Figure $4 \mathrm{~B}$ and Figure 4C). These data demonstrate that SC inhibits NF- $\mathrm{kB}$ activation in LPS-stimulated BV-2 microglia and that this mechanism may contribute to the regulation of neuroinflammatory events.

Free radical scavenging activities of SC

The potential of the SC extract to quench free radicals such as DPPH and alkyl radicals was investigated. DPPH is a stable free radical that accepts an electron or hydrogen radical to become a stable diamagnetic molecule. DPPH has been used to evaluate free radical scavenging activity of natural antioxidants. The capacity of SC to 
(A)

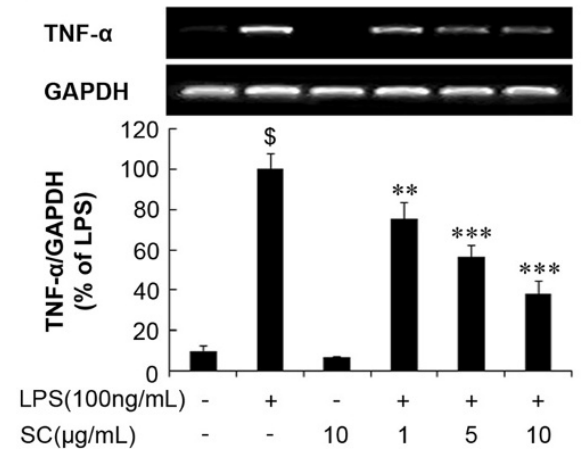

(B)

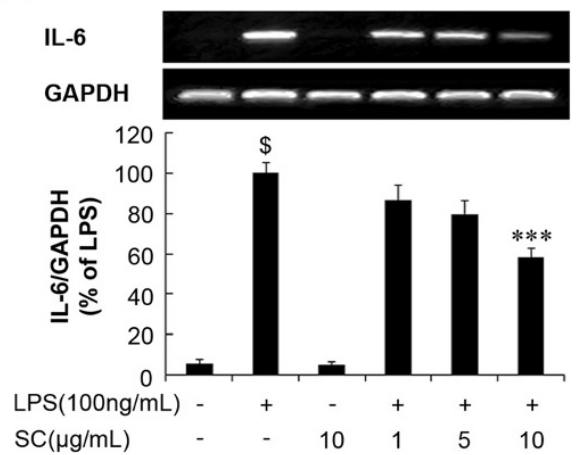

Figure 3 Effect of the SC extract on pro-inflammatory cytokines in LPS-stimulated BV-2 microglia. Cells were pretreated with the indicated concentrations of SC for $1 \mathrm{~h}$ before LPS (100 ng/mL) treatment. After incubation with LPS for $6 \mathrm{~h}$, tumor necrosis factor (TNF)- $a$ (A) and interleukin (IL)-6 (B) mRNA levels were determined by reverse transcription-polymerase chain reaction. Data are mean \pm standard error $(n=3)$ for three independent experiments. ${ }^{\$} p<0.001$, compared with control group; ${ }^{*} p<0.05$ and ${ }^{* * *} p<0.001$ compared with LPS-treated group. SC: Saururus chinensis, LPS: lipopolysaccharide.

scavenge DPPH was measured by ESR spectrometry, and the results are shown in Figure $5 \mathrm{~A}$. DPPH radical scavenging activities of $\mathrm{SC}$ at various concentrations $(0.031,0.062,0.125,0.25,0.5,1$, and $2 \mathrm{mg} / \mathrm{mL})$ were $38.9 \pm 1.5 \%, 53.2 \pm 2.4 \%, 63.0 \pm 3.1 \%, 77.8 \pm 1.6 \%, 86.8 \pm$ $2.2 \%, 88.9 \pm 1.3 \%$, and $90.8 \pm 0.9 \%$, respectively with an $\mathrm{IC}_{50}$ value of $0.055 \pm 0.004 \mathrm{mg} / \mathrm{mL}$. The alkyl radical spin adduct of 4-POBN/free radicals was generated from $\mathrm{AAPH}$ at $37^{\circ} \mathrm{C}$ for $30 \mathrm{~min}$, and a decrease in ESR signals was observed with a dose increases of SC (Figure 5B). The alkyl radical scavenging activities of SC $(025,0.5$, and $1 \mathrm{mg} / \mathrm{mL}$ ) were $41.0 \pm 1.3 \%, 56.0 \pm 0.5 \%$, and $62.1 \pm$ $5.6 \%$, respectively, with an $\mathrm{IC}_{50}$ value of $0.359 \pm 0.07 \mathrm{mg} / \mathrm{mL}$. These data show that SC possesses significant antioxidant activity.

\section{HPLC fingerprint analysis of SC and the effect of active constituent on proinflammatory cytokine expression in LPS stimulated BV-2 microglia}

HPLC fingerprinting analysis of SC extract showed several peaks indicating a wide mixture of compounds. Earlier works indicated that SC extract contained polyphenolic compounds such as saucerneol D/F, sauchinone, manassantin $\mathrm{A}$ and $\mathrm{B}$ dineolignans and quercetin (QCT) flavonol glycosides [24-28]. Although the peaks obtained were below the level of quantification (Figure 6A), we compared with QCT as reference standard. Based on the retention time and UV spectrum we identified that SC extract used in our study contained QCT as one of the major constituents (Figure 6B). Further, to confirm the protective effects of QCT on NO release and cytokine expression, indicated concentrations of QCT $(1,5$, and $10 \mu \mathrm{M})$ were pretreated to BV-2 cells stimulated with or without LPS (100 ng/mL). QCT alone at $10 \mu \mathrm{M}$ did not exhibit any signs of toxicity in BV-2 cells (data not shown), however QCT (1, 5 and $10 \mu \mathrm{M})$ significantly and concentration dependently, suppressed LPS-induced production of NO (Figure 6C) and also attenuated the increase in IL-6, COX-2 and iNOS expression in a concentration-dependent manner (Figure 6D).

\section{Discussion}

In the present study, we demonstrated that SC extract pre-treatment regulated the neuroinflammatory events in LPS-stimulated BV-2 microglial cells in several aspects. SC extract reduced LPS-stimulated NO production in BV-2 microglia cells in a concentrationdependent manner. SC also suppressed iNOS gene expression at the mRNA and protein levels. These results suggest that a significant decrease in NO release by $\mathrm{SC}$ extract is linked with inhibiting upstream iNOS gene expression.

$\mathrm{COX}$ is a key rate-limiting enzyme in the conversion of arachidonic acid to prostaglandins, which are lipid metabolites involved in several physiological and pathological processes, including neuroinflammation [29,30]. COX-2 is mainly induced in response to inflammatory stimuli, which led to the concept that inhibiting COX-2 can reduce inflammatory processes in neurodegenerative diseases [31]. Several in vivo and in vitro studies have demonstrated that COX-2 is markedly up regulated in rodent brain microglia and in BV-2 microglia after LPS treatment [32-34]. In the current study we determined whether $\mathrm{SC}$ was associated with $\mathrm{COX}$ expression in LPS-stimulated BV-2 microglia cells. As a result, COX-2 mRNA and protein expression was dose-dependently suppressed by SC treatment (1,5 and $10 \mu \mathrm{g} / \mathrm{mL})$. Several reports have indicated that iNOS and COX-2 are induced in various types of CNS diseases [35,36]. iNOS and COX-2 are expressed in glial cells of the substantia 
(A)

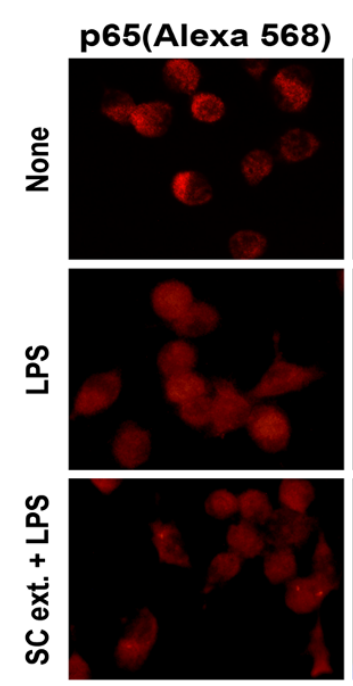

(B)

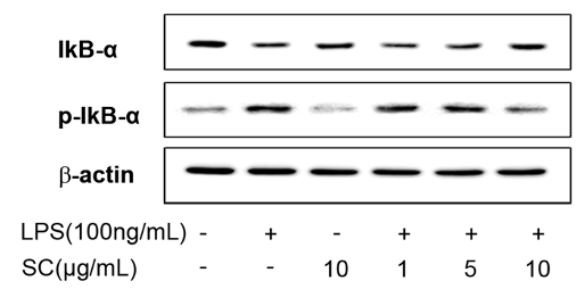

Hoechst

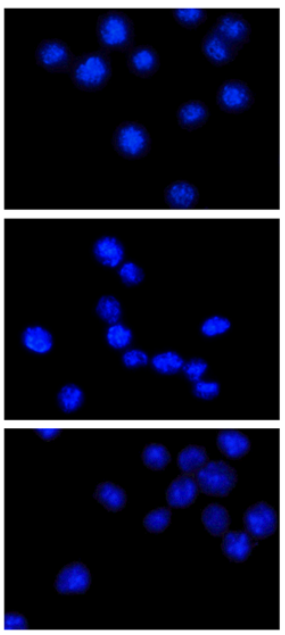

(C)

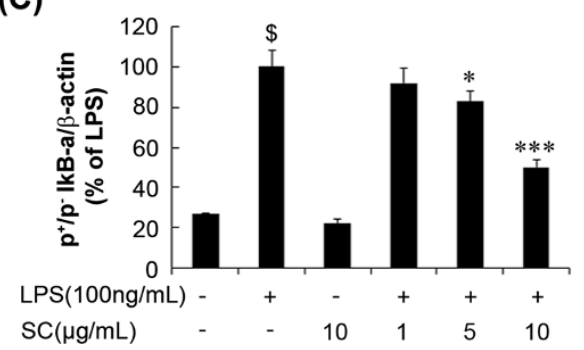

Figure 4 Effect of the SC extract on nuclear factor (NF)-KB activity in LPS-stimulated BV-2 microglia. BV-2 microglia cells were seeded at a density of $1 \times 10^{5}$ cells/well on a 12-well plate. BV-2 microglia cells were stimulated with $100 \mathrm{ng} / \mathrm{mL}$ LPS in the absence or presence of the SC $(10 \mathrm{\mu g} / \mathrm{mL})$ extract that had been added $1 \mathrm{~h}$ before stimulation. At $30 \mathrm{~min}$ after LPS stimulation, sub-cellular location of the NF-KB p65 subunit was determined by double-immunofluorescence labeling assay (A). Cells were treated with the indicated dose of SC $30 \mathrm{~min}$ before LPS (100 ng/mL) treatment. Total protein was subjected to $10 \%$ sodium dodecyl sulfate-polyacrylamide gel electrophoresis followed by Western blotting using anti-lkB- $a$ and anti-p (phospho)-IkB-a (B). Densitometric analysis of plkB-a and IkB-a are represented in the panel. Results are expressed as a ratio of phospho/ nonphospo IkB-a/ $\beta$-actin (C). Data are mean \pm standard error $(n=3)$ of three independent experiments. ${ }^{\$} p<0.001$, compared with control group; ${ }^{*} \mathrm{p}<0.05$ and ${ }^{* *} \mathrm{p}<0.001$ compared with LPS-treated group. SC: Saururus chinensis, LPS: lipopolysaccharide.

nigra in post-mortem patients with PD [37]. Therefore, attenuating the induction of iNOS and COX-2 in activated microglia could inhibit neuroinflammation.

It was well documented that pro-inflammatory cytokines such as TNF- $\alpha$, IL- $1 \beta$, and IL- 6 activate iNOS gene expression in rodent glial and muscle cells [36,38,39]. The likelihood of the involvement of SC in attenuating such factors is supported by our observations that proinflammatory mediators produced by LPS treatment such as TNF- $\alpha$ and IL- 6 were suppressed by SC in BV-2 microglial cells at mRNA levels. This indicated that SC extract may be an effective anti-neuroinflammatory therapeutic agent.

NF- $\mathrm{kB}$ is a key transcription factor that is activated by several cellular signal transduction pathways associated with the regulation of cell survival and the expression of proinflammatory cytokines and enzymes such as iNOS, IL- 6 and TNF- $\alpha[40,41]$. The molecular mechanisms of NF- $\kappa B$ activation have been well studied, and they involve activation of a cascade of cytoplasmic proteins and nuclear translocation of the NF-kB p65 subunit [42,43]. We found that $\mathrm{SC}$ extract attenuated LPS-induced IкB- $\alpha$ degradation as well as nuclear translocation of p65 in BV-2 microglia, indicating that SC extract inhibits iNOS and TNF- $\alpha$ gene expression in microglia and may be involved in the inhibition of NF- $\mathrm{kB}$ activation as a possible mechanism.

Previous studies have demonstrated that the specific iNOS inhibitors reduced NO and act as a potent antioxidant by inhibiting ROS production in LPS-simulated microglia $[44,45]$. Reports also showed that several polyphenolic compounds with immense antioxidant potential possess anti-neuroinflammatory properties [46-48]. In light of such reports, in our present study, we found that the SC significantly scavenged DPPH and alkyl free radicals exhibiting potent antioxidant actions. The antioxidant potential of SC might partly be responsible in inhibiting neuroinflammation in LPS-stimulated BV-2 microglial cells. 
(A)
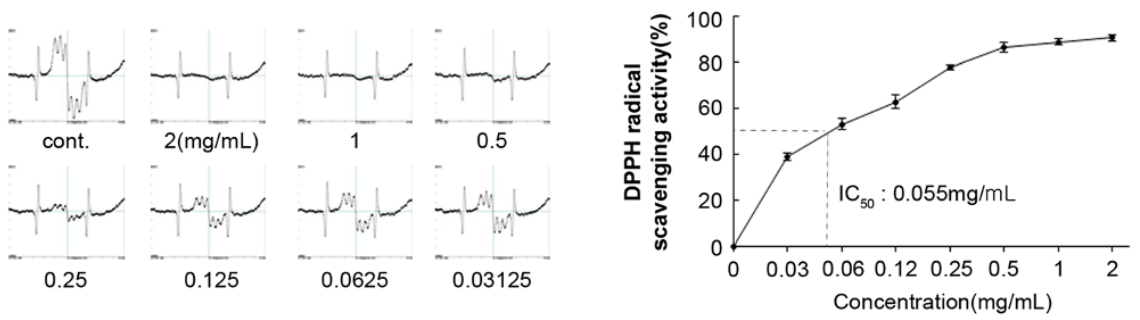

(B)
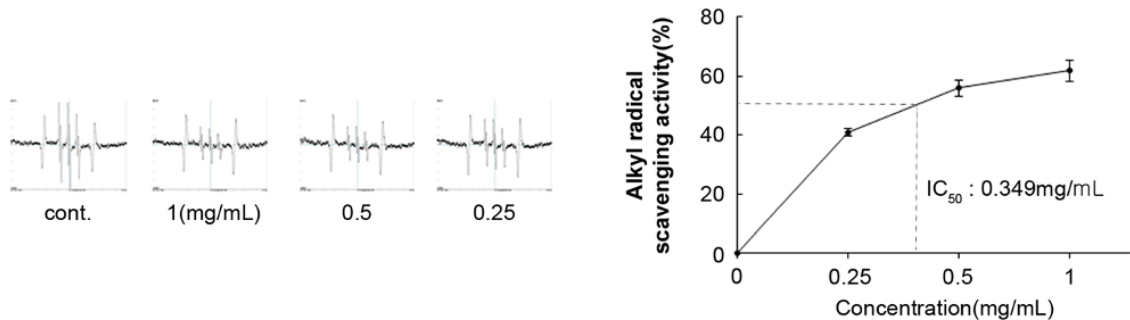

Figure 5 Free radical scavenging effects of the SC extract. (A) Left: Electron spin resonance (ESR) spectra of DPPH radical scavenging. Right: Relationship between the signal intensity of the DPPH radical and various concentrations of SC. (B) Left: ESR spectra of 2-(4-pyridyl-1-oxide)-N-tbutylnitrone (POBN)-trapped alkyl radical scavenging. Right: Relationship between the signal intensity of the POBN-alkyl radicals and the various concentrations of SC. SC: Saururus chinensis.

(A)

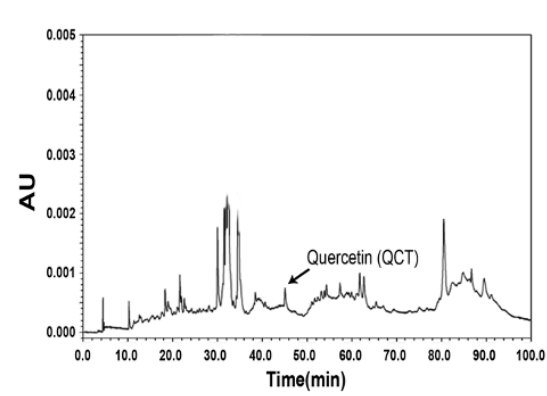

(C)

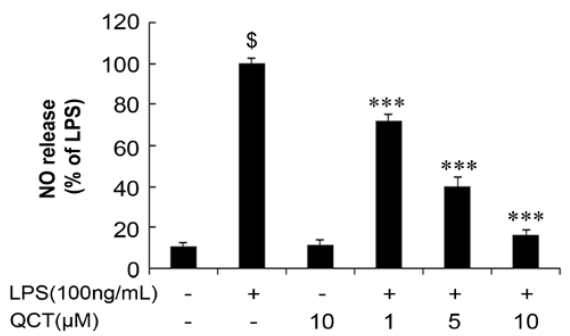

(B)

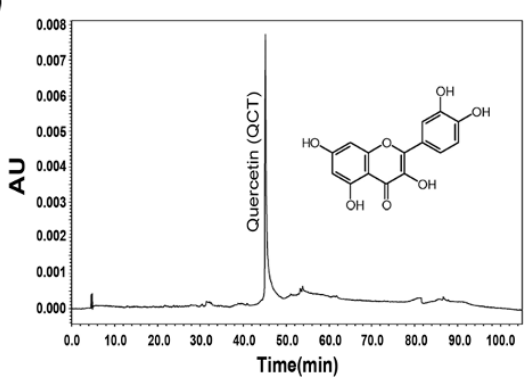

(D)

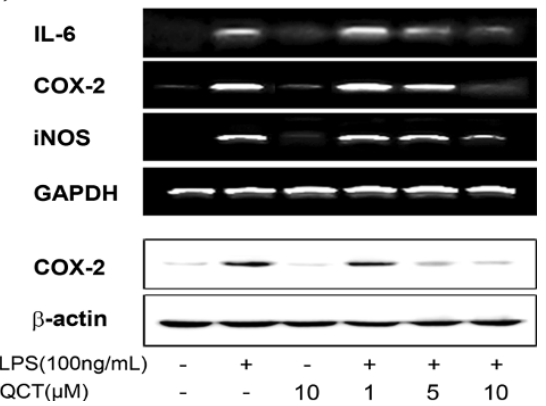

Figure 6 High performance liquid chromatography (HPLC) fingerprinting of SC extract and the effect of QCT on nitric oxide (NO), interleukin (IL)-6, cyclooxygenase (COX)-2, and inducible nitric oxide synthase (iNOS) production in LPS-stimulated BV-2 microglia. HPLC fingerprint analysis of SC (A) and QCT (B). BV-2 cells were incubated for $24 \mathrm{~h}$ with LPS $(100 \mathrm{ng} / \mathrm{mL})$ in the presence or absence of the indicated concentrations of SC. The nitrite in the medium was determined by NO assay (C). Several biomarkers were analyzed followed by reverse transcription-polymerase chain reaction and Western blotting (D). Data are mean \pm standard error $(n=3)$ of three independent experiments. ${ }^{\$} p<0.001$, compared with control group; ${ }^{* * *}$ < 0.001 compared with LPS-treated group. SC: Saururus chinensis, LPS: lipopolysaccharide, QCT: quercetin. 
SC contains several compounds such as saucerneol D/F, sauchinone, manassantin $\mathrm{A}$ and $\mathrm{B}$ dineolignans and quercetin (QCT) flavonol glycosides [24-28]. These compounds were well reported to possess various biological activities including anti-inflammatory activities [11,26,49-52]. In our present study HPLC fingerprint analysis showed that SC extract contained QCT as one of the major compounds compared with reference standard.

QCT, a flavonoid polyphenolic compound found in many natural herbs showed protective effects in both in vivo and in vitro neurodegenerative models based on its antioxidant function [46,53-56]. Furthermore, QCT inhibited gene expression of NO, iNOS, COX-2, and IL-6 in LPS-stimulated BV-2 cells. Therefore, QCT and other antioxidant polyphenolic compounds present in the $\mathrm{SC}$ extract might partly contribute and enhance the antineuroinflammatory effects in LPS-stimulated BV-2 cells.

\section{Conclusions}

In summary, SC exerted anti-neuroinflammatory actions by inhibition of major neuroinflammatory mediators and cytokines in LPS-stimulated BV-2 microglial cells. Mechanistic study showed that $\mathrm{SC}$ might act by regulating NF- $\kappa B$ signaling pathways and anti-oxidant defense mechanisms. The antioxidant potential of SC might also be responsible for such beneficial effects. Based on the traditional claims and the present data SC can be potentially used in treating several inflammatory- mediated neurodegenerative diseases.

\section{Abbreviations}

BSA: Bovine Serum Albumin; COX-2: Cyclooxygenase-2; DMEM: Dimethyl Sulfoxide; FBS: Fetal Bovine Serum; GAPDH: Glyceraldehydes-3-Phosphate Dehydrogenase; HPLC: High-performance liquid chromatography; IKB-a: Inhibitory protein kappa B alpha; IL-1 $\beta$ : Interleukin-1 beta; IL-6: Interleukin-6; iNOS: Inducible Nitric Oxide Synthase; LPS: Lipopolysaccharide; MTT: p-nitrophenyl phosphate, and 3-(4,5-dimethylthiazol-2-yl)-2,5-diphenyltetrazolium bromide; NF-kB: Nuclear factor kappa B; NO: Nitric Oxide; PBS: Phosphate-buffered saline; PD: Parkinson's Disease; RT-PCR: Reverse transcription polymerase chain reaction; SDS: Sodium Dodecyl Sulfate; TNF-a: Tumor necrosis factor-a.

\section{Competing interests}

The authors declare that they have no competing interests.

\section{Authors' contributions}

B-WK, S-YP and J-WH have made contributions to the acquisition and analysis of data. B-WK, SK, P-JP, J-HL and D-KC were involved in the interpretation of data. B-WK, SK and D-KC were involved in designing the study and drafting the manuscript. All authors read and gave final approval for the version submitted for publication.

\section{Acknowledgement}

This work was supported by the National Research Foundation of Korea(NRF) grant funded by the Korea government(MEST) (No. 2014R1A2A2A04007791).

\section{Author details}

${ }^{1}$ Department of Biotechnology, Konkuk University, Chungju, Korea.

${ }^{2}$ Department of Biomedical chemistry, Konkuk University, Chungju, Korea.

Received: 13 March 2014 Accepted: 19 September 2014

Published: 16 December 2014

\section{Reference}

1. Kim YS, Joh TH: Microglia, major player in the brain inflammation: their roles in the pathogenesis of Parkinson's disease. Exp Mol Med 2006, 38(4):333-347

2. Koning N, Bo L, Hoek RM, Huitinga I: Downregulation of macrophage inhibitory molecules in multiple sclerosis lesions. Ann Neurol 2007 62(5):504-514

3. Krause $\mathrm{DL}$, Muller $\mathrm{N}$ : Neuroinflammation, microglia and implications for anti-inflammatory treatment in Alzheimer's disease. Int J Alzheimers Dis 2010, 2010:732806.

4. Moller T: Neuroinflammation in Huntington's disease. J Neural Transm 2010, 117(8):1001-1008.

5. Graeber MB, Streit WJ: Microglia: biology and pathology. Acta Neuropathol 2010, 119(1):89-105.

6. Chung BS, Shin MG: Dictionary of Korean Folk Medicine. Seoul: Young Lim Publishing Co., Ltd.; 1990

7. Quan Z, Lee YJ, Yang JH, Lu Y, Li Y, Lee YK, Jin M, Kim JY, Choi JH, Son JK, Chang HW: Ethanol extracts of Saururus chinensis suppress ovalbumin-sensitization airway inflammation. J Ethnopharmacol 2010, 132(1):143-149.

8. Lee E, Haa K, Yook JM, Jin MH, Seo CS, Son KH, Kim HP, Bae KH, Kang SS, Son JK, Chang HW: Anti-asthmatic activity of an ethanol extract from Saururus chinensis. Biol Pharm Bull 2006, 29(2):211-215.

9. Jung MH, Song MC, Bae K, Kim HS, Kim SH, Sung SH, Ye SK, Lee KH, Yun YP, Kim TJ: Sauchinone attenuates oxidative stress-induced skeletal muscle myoblast damage through the down-regulation of ceramide. Biol Pharm Bull 2011, 34(4):575-579.

10. Cho HY, Cho CW, Song YS: Antioxidative and anti-inflammatory effects of Saururus chinensis methanol extract in RAW 264.7 macrophages. J Med Food 2005, 8(2):190-197.

11. Han HJ, Li M, Son JK, Seo CS, Song SW, Kwak SH, Bae HB: Sauchinone, a lignan from Saururus chinensis, attenuates neutrophil pro-inflammatory activity and acute lung injury. Int Immunopharmacol 2013, 17(2):471-477.

12. Yoo HJ, Kang HJ, Jung HJ, Kim K, Lim CJ, Park EH: Anti-inflammatory, anti-angiogenic and anti-nociceptive activities of Saururus chinensis extract. J Ethnopharmacol 2008, 120(2):282-286.

13. Choi MS, Kim EC, Lee HS, Kim SK, Choi HM, Park JH, Han JB, An HJ, Um JY, Kim HM, Han AR, Hong MC, Bae H, Min BI: Inhibitory effects of Saururus chinensis (LOUR.) BAILL on the development of atopic dermatitis-like skin lesions in NC/Nga mice. Biol Pharm Bull 2008, 31(1):51-56.

14. Lee YJ, Kim J, Yi JM, Oh SM, Kim NS, Kim H, Oh DS, Bang OS, Lee J: Anti-proliferative neolignans from Saururus chinensis against human cancer cell lines. Biol Pharm Bull 2012, 35(8):1361-1366.

15. Sung SH, Kim YC: Hepatoprotective diastereomeric lignans from Saururus chinensis herbs. J Nat Prod 2000, 63(7):1019-1021.

16. Kim BW, Koppula S, Hong SS, Jeon SB, Kwon JH, Hwang BY, Park EJ, Choi DK: Regulation of microglia activity by glaucocalyxin-A: attenuation of lipopolysaccharide-stimulated neuroinflammation through NF-kappaB and p38 MAPK signaling pathways. PLoS One 2013, 8(2):e55792.

17. Green LC, Wagner DA, Glogowski J, Skipper PL, Wishnok JS, Tannenbaum SR: Analysis of nitrate, nitrite, and [15 N]nitrate in biological fluids. Anal Biochem 1982, 126(1):131-138.

18. Kim BW, Koppula S, Kim JW, Lim HW, Hwang JW, Kim IS, Park PJ, Choi DK: Modulation of LPS-stimulated neuroinflammation in BV-2 microglia by Gastrodia elata: 4-hydroxybenzyl alcohol is the bioactive candidate. J Ethnopharmacol 2012, 139(2):549-557.

19. Nanjo F, Goto K, Seto R, Suzuki M, Sakai M, Hara Y: Scavenging effects of tea catechins and their derivatives on 1,1-diphenyl-2-picrylhydrazyl radical. Free Radic Biol Med 1996, 21(6):895-902.

20. Wang W, Ji P, Dow KE: Corticotropin-releasing hormone induces proliferation and TNF-alpha release in cultured rat microglia via MAP kinase signalling pathways. J Neurochem 2003, 84(1):189-195.

21. Hofmann U, Heuer S, Meder K, Boehler J, Lange V, Quaschning T, Ertl G, Bonz A: The proinflammatory cytokines TNF-alpha and IL-1 beta impair economy of contraction in human myocardium. Cytokine 2007, 39(3):157-162.

22. Siebenlist U, Franzoso G, Brown K: Structure, regulation and function of NF-kappa B. Annu Rev Cell Biol 1994, 10:405-455.

23. Nomura Y: NF-kappaB activation and IkappaB alpha dynamism involved in iNOS and chemokine induction in astroglial cells. Life Sci 2001, 68(15):1695-1701. 
24. Li B, Lee DS, Choi HG, Kim KS, Kang DG, Lee HS, Jeong GS, Kim YC: Sauchinone suppresses pro-inflammatory mediators by inducing heme oxygenase-1 in RAW264.7 macrophages. Biol Pharm Bull 2011, 34(10):1566-1571.

25. Lee AK, Sung SH, Kim YC, Kim SG: Inhibition of lipopolysaccharide-inducible nitric oxide synthase, TNF-alpha and COX-2 expression by sauchinone effects on I-kappaBalpha phosphorylation, C/EBP and AP-1 activation. Br J Pharmacol 2003, 139(1):11-20.

26. Jang EY, Yang $\mathrm{CH}$, Han MH, Choi YH, Hwang M: Sauchinone suppresses lipopolysaccharide-induced inflammatory responses through Akt signaling in BV2 cells. Int Immunopharmacol 2012, 14(2):188-194.

27. LU Y, Li Y, Seo CS, Murakami M, Son JK, Chang HW: Saucerneol D inhibits eicosanoid generation and degranulation through suppression of Syk kinase in mast cells. Food Chem Toxicol 2012, 50(12):4382-4388.

28. Lu Y, Suh SJ, Kwak CH, Kwon KM, Seo CS, Li Y, Jin Y, Li X, Hwang SL, Kwon O, Chang YC, Park YG, Park SS, Son JK, Kim CH, Chang HW: Saucerneol F, a new lignan, inhibits iNOS expression via MAPKs, NF-kappaB and AP-1 inactivation in LPS-induced RAW264.7 cells. Int Immunopharmacol 2012, 12(1):175-181.

29. Vlad SC, Miller DR, Kowall NW, Felson DT: Protective effects of NSAIDs on the development of Alzheimer disease. Neurology 2008, 70(19):1672-1677.

30. Hernan MA, Logroscino G, Garcia Rodriguez LA: Nonsteroidal antiinflammatory drugs and the incidence of Parkinson disease. Neurology 2006, 66(7):1097-1099.

31. Farooqui $A A$, Horrocks $L A$, Farooqui $T$ : Modulation of inflammation in brain: a matter of fat. J Neurochem 2007, 101(3):577-599.

32. Bauer MK, Lieb K, Schulze-Osthoff K, Berger M, Gebicke-Haerter PJ, Bauer J, Fiebich BL: Expression and regulation of cyclooxygenase-2 in rat microglia. Eur J Biochem 1997, 243(3):726-731.

33. Lau LM, Wolter JK, Lau JT, Cheng LS, Smith KM, Hansford LM, Zhang L, Baruchel S, Robinson F, Irwin MS: Cyclooxygenase inhibitors differentially modulate p73 isoforms in neuroblastoma. Oncogene 2009, 28(19):2024-2033.

34. Minghetti L, Polazzi E, Nicolini A, Greco A, Levi G: Possible role of microglial prostanoids and free radicals in neuroprotection and neurodegeneration. Adv Exp Med Biol 1999, 468:109-119.

35. Teismann P, Vila M, Choi DK, Tieu K, Wu DC, Jackson-Lewis V, Przedborski S: COX-2 and neurodegeneration in Parkinson's disease. Ann N Y Acad Sci 2003, 991:272-277.

36. Hunot $\mathrm{S}$, Hartmann A, Hirsch EC: The inflammatory response in the Parkinson brain. Clinical Neuroscience Research 2001, 1(6):434-443.

37. Knott C, Stern G, Wilkin GP: Inflammatory regulators in Parkinson's disease: iNOS, lipocortin-1, and cyclooxygenases-1 and -2. Mol Cell Neurosci 2000, 16(6):724-739

38. González-Scarano FBG: Microglia as mediators of inflammatory and degenerative diseases. Annu Rev Neurosci 1999, 22:219-240.

39. Blasi E, Barluzzi R, Bocchini V, Mazzolla R, Bistoni F: Immortalization of murine microglial cells by a v-raf/v-myc carrying retrovirus. J Neuroimmunol 1990, 27(2-3):229-237.

40. Baeuerle PA, Henkel T: Function and activation of NF-kappa B in the immune system. Annu Rev Immunol 1994, 12:141-179.

41. Baldwin AS: The transcription factor NF-kappa B and human disease. Journal of Clinical Investigation 2001, 107(1):3-6.

42. Delhase M, Li NX, Karin M: Signalling pathways - Kinase regulation in inflammatory response. Nature 2000, 406(6794):367-368.

43. Karin M, Ben-Neriah Y: Phosphorylation meets ubiquitination: the control of NF-[kappa]B activity. Annu Rev Immunol 2000, 18:621-663.

44. Hemmer K, Fransen L, Vanderstichele H, Vanmechelen E, Heuschling P: An in vitro model for the study of microglia-induced neurodegeneration: involvement of nitric oxide and tumor necrosis factor-alpha. Neurochem Int 2001, 38(7):557-565.

45. Reis K, Halldin J, Fernaeus S, Pettersson C, Land T: NADPH oxidase inhibitor diphenyliodonium abolishes lipopolysaccharide-induced down-regulation of transferrin receptor expression in N2a and BV-2 cells. Journal of Neuroscience Research 2006, 84(5):1047-1052.

46. Bureau G, Longpre F, Martinoli MG: Resveratrol and quercetin, two natural polyphenols, reduce apoptotic neuronal cell death induced by neuroinflammation. J Neurosci Res 2008, 86(2):403-410.

47. Casado R, Landa A, Calvo J, Garcia-Mina JM, Marston A, Hostettmann K, Calvo Ml: Anti-inflammatory, antioxidant and antifungal activity of Chuquiraga spinosa. Pharm Biol 2011, 49(6):620-626.
48. Geraghty DP, Ahuja KD, Pittaway J, Shing C, Jacobson GA, Jager N, Jurkovic S, Narkowicz C, Saunders Cl, Ball M, Pinkard A, Vennavaram RR, Adams MJ: In vitro antioxidant, antiplatelet and anti-inflammatory activity of Carpobrotus rossii (pigface) extract. J Ethnopharmacol 2011, 134(1):97-103.

49. Jung JY, Lee KY, Lee MY, Jung D, Cho ES, Son HY: Antioxidant and antiasthmatic effects of saucerneol $D$ in a mouse model of airway inflammation. Int Immunopharmacol 2011, 11(6):698-705.

50. Li B, Lee YJ, Kim YC, Yoon JJ, Lee SM, Lee YP, Kang DG, Lee HS: Sauchinone from Saururus chinensis protects vascular inflammation by heme oxygenase-1 induction in human umbilical vein endothelial cells. Phytomedicine 2014, 21(2):101-108.

51. Park HC, Bae HB, Jeong CW, Lee SH, Jeung HJ, Kwak SH: Effect of manassantin $B$, a lignan isolated from Saururus chinensis, on lipopolysaccharide-induced interleukin-1beta in RAW 264.7 cells. Korean J Anesthesiol 2012, 62(2):161-165.

52. Caddeo C, Diez-Sales O, Pons R, Fernandez-Busquets X, Fadda AM, Manconi M: Topical Anti-Inflammatory Potential of Quercetin in Lipid-Based Nanosystems: In Vivo and In Vitro Evaluation. Pharm Res 2014, 31(4):959-968.

53. Woo KW, Moon E, Park SY, Kim SY, Lee KR: Flavonoid glycosides from the leaves of Allium victorialis var. platyphyllum and their anti-neuroinflammatory effects. Bioorg Med Chem Lett 2012, 22(24):7465-7470.

54. Bournival J, Plouffe M, Renaud J, Provencher C, Martinoli MG: Quercetin and Sesamin Protect Dopaminergic Cells from MPP+-Induced Neuroinflammation in a Microglial (N9)-Neuronal (PC12) Coculture System. Oxid Med Cell Longev 2012, 2012:921941.

55. Kao TK, Ou YC, Raung SL, Lai CY, Liao SL, Chen CJ: Inhibition of nitric oxide production by quercetin in endotoxin/cytokine-stimulated microglia. Life Sci 2010, 86(9-10):315-321.

56. Chen JC, Ho FM, Pei-Dawn Lee C, Chen CP, Jeng KC, Hsu HB, Lee ST, Wen Tung W, Lin WW: Inhibition of iNOS gene expression by quercetin is mediated by the inhibition of IkappaB kinase, nuclear factor-kappa B and STAT1, and depends on heme oxygenase- 1 induction in mouse BV-2 microglia. Eur J Pharmacol 2005, 521(1-3):9-20.

doi:10.1186/1472-6882-14-502

Cite this article as: Kim et al:: Attenuation of inflammatory-mediated neurotoxicity by Saururus chinensis extract in LPS-induced BV-2 microglia cells via regulation of NF-KB signaling and anti-oxidant properties. BMC Complementary and Alternative Medicine 2014 14:502.

\section{Submit your next manuscript to BioMed Central and take full advantage of:}

- Convenient online submission

- Thorough peer review

- No space constraints or color figure charges

- Immediate publication on acceptance

- Inclusion in PubMed, CAS, Scopus and Google Scholar

- Research which is freely available for redistribution 